artelogie

\section{Artelogie}

Recherche sur les arts, le patrimoine et la littérature de l'Amérique latine

$13 \mid 2019$

Violeta Parra: authenticité, primitivisme et processus d'exotisme chez les artistes latino-américains.

\title{
Violeta Parra: procesos de reconocimiento y formas de consagración en una trayectoria de artista
}

Marisol Facuse, Eric Villagordo y Juan Enrique Serrano Moreno

\section{(2) OpenEdition \\ Journals}

Edición electrónica

URL: http://journals.openedition.org/artelogie/3513

DOI: 10.4000/artelogie.3513

ISSN: $2115-6395$

Editor

Association ESCAL

Referencia electrónica

Marisol Facuse, Eric Villagordo et Juan Enrique Serrano Moreno, « Violeta Parra: procesos de reconocimiento y formas de consagración en una trayectoria de artista », Artelogie [En ligne], 13 | 2019, mis en ligne le 07 janvier 2019, consulté le 19 avril 2019. URL : http:// journals.openedition.org/artelogie/3513 ; DOI : 10.4000/artelogie.3513

Este documento fue generado automáticamente el 19 avril 2019.

Association ESCAL 


\title{
Violeta Parra: procesos de reconocimiento y formas de consagración en una trayectoria de artista
}

\author{
Marisol Facuse, Eric Villagordo y Juan Enrique Serrano Moreno
}

\section{Introducción}

1 El presente número de la revista reúne textos sobre la figura de la artista chilena Violeta Parra (1917-1967) preparados por investigadores.as de diversas disciplinas (historia, sociología del arte, musicología, historia cultural), con el propósito de dilucidar algunos de los elementos que han constituido la singularidad de su trayectoria artística.

2 V. Parra representa hoy en día una de las artistas chilenas de mayor alcance y reconocimiento internacional. Si bien su obra y su figura han sufrido cierto ostracismo en su país de origen, las instituciones de la cultura han buscado en parte compensar este olvido con una serie de conmemoraciones oficiales que han tenido lugar en el aniversario de los cien años de su nacimiento. Entre los diferentes actos y homenajes organizados en 2017, cabe destacar el "Coloquio Internacional Violeta Parra" organizado por el Departamento de Estudios del Consejo Nacional de la Cultura y las Artes de Chile (CNCA) celebrado el 29 y 30 de agosto, que reunió en el Centro Cultural Gabriela Mistral en Santiago a 48 investigadores de 8 países ${ }^{1}$. El origen del presente número especial se encuentra en dicho coloquio, en el que participaron los coordinadores de este número, que representa a nuestro entender uno de los encuentros académicos dedicados a $\mathrm{V}$. Parra más ambiciosos realizados hasta la fecha ${ }^{2}$.

Con todo, encontramos aún un déficit de estudios dedicados a V. Parra que adolecen de una cierta dispersión y compartimentación disciplinar que este número pretende contribuir a paliar. Y ello adoptando explícitamente una perspectiva multidisciplinar 
fundada sobre un cuestionamiento sociológico sobre las implicancias de la singularidad de su trayectoria.

4 De manera general, Violeta ha sido situada como una figura fundante de una multiplicidad de tradiciones musicales, poéticas y artísticas, para algunos.as su obra musical inaugura el género de la canción comprometida en Chile, o protest song en los años 1960, también se la reconoce como una de las primeras en anticipar un movimiento cultural de retorno al folklorismo, o folksong, una forma de retorno a la naturaleza y la ruralidad, que sentó las bases para movimientos hippies y contra-culturales de la segunda mitad del siglo pasado. Paralelamente, su obra plástica (Fundación Violeta Parra, 2007; Museo Violeta Parra, 2015), ha sido interpretada como un anticipo de corrientes como el indigenismo o el art brut (según la definición de Jean Dubuffet en 1948) en las artes visuales, un movimiento catalogado por los norteamericanos como un art outsider, según la definición posterior de Roger Cardinal en 1972. Es decir que muy pronto en el siglo veinte, participo a una sensibilidad que se nombró primitivismo, que fue iniciada por Paul Gauguin, sensibilidad que se interroga sobre las relaciones desiguales entre culturas ${ }^{3}$.

\section{Una trayectoria artística en tensión: encontrar su lugar de artista}

5 Como muchos.as de sus biógrafos (Herrero, 2017; Oviedo, 1990) lo han destacado, la trayectoria de Violeta Parra está atravesada por una serie de tensiones, sin embargo, es lo propio de los artistas del siglo veinte instaurar una relación con su época, amoldándose $u$ oponiéndose a los modelos de producción artísticos dominantes, así como a modelos estéticos, a veces contradictorios. En el caso de Violeta estas tensiones fluctuaban entre campo y ciudad, tradición y originalidad, saberes musicales y expresionismo del canto, etnicidad y artisticidad universal. Estas tensiones han sido teorizadas por autores como Mickael Baxandall (1989), para quien los artistas deben negociar con su cultura, enfrentándose cada uno a un conjunto de directivas (modelos o patterns en inglés) a partir de las cuales, elaboran sus obras. Nathalie Heinich (2005) hace referencia al régimen de singularidad profesional del artista, una representación heredada del romanticismo, que podríamos entender en oposición a la ingenuidad del modernismo en ruptura en el siglo XX. Violeta Parra parece situarse al cruce de todas estas directivas que caracterizan la identidad y del estatuto del artista, donde la condición de género resulta insoslayable, considerando los obstáculos suplementarios que deben enfrentar las mujeres, para lograr la consagración de una carrera artística.

6 Desde una perspectiva sociológica podemos decir que su trayectoria de artista estuvo sometida a distintas contradicciones presentes tanto en el contexto estructural ideológico chileno (depreciación de la cultura campesina e indígena a favor de la modernidad urbana) como en el contexto artístico (predominio de una noción de éxito, de la industria musical de masas y de la difusión de artistas y géneros musicales extranjeros). Desde el renacimiento europeo, la figura del artista es eminentemente urbana en oposición al campo y a la naturaleza a partir de una representación de la ciudad como el lugar de la cultura, distante del mundo salvaje y de las periferias, concebidos como bárbaros o incultos. Esas estructuras contextuales, fuertemente cristalizadas en el imaginario moderno, se modifican entre los años 1940 y 1970, evolucionando parcialmente, gracias a un movimiento colectivo de investigadores y artistas que se pudo llamar según el país, 
neo-folclor, tropicalismo, indigenismo, neo-primitivismo, arte bruto en Europa o arte outsider en los años 1970 en Estados Unidos.

7 A este respecto, sobre las tensiones inherentes al carácter ecléctico de la obra de V. Parra, Ericka Verda propone, en su contribución a este número, un análisis sobre su proceso formativo durante su primera estadía europea entre 1955 y 1956. Una experiencia que marcó su posterior trayectoria, en la que penetró los circuitos culturales que abarca son los del socialismo modernista, la pachanga latinoamericana parisina, la folklorización comunista, el folk revival británico, y la etnografía neocolonialista.

8 Violeta Parra se enfrentó a un campo artístico musical y de artes plásticas que no era autónomo (en el sentido de Bourdieu), en el cual no existía el estatuto de cantautor(a). En consecuencia, tuvo que trabajar arduamente para ganar su vida en numerosas grabaciones, giras y conciertos, hasta asentarse en la última parte de su vida la creación con la Carpa de La Reina, en periferia de Santiago de Chile en 1965. Sobre este último episodio en la vida de V. Para, Ariel Mamani nos propone un análisis historiográfico. Analiza la carpa tanto como la continuación de las "peñas folclóricas", entendidas como espacios de socialización de los artistas de la época, como un proyecto experimental de fusión de los elementos modernizadores y arcaicos.

9 El ideal de "vivir de su arte" ha sido siempre un compromiso muy difícil de alcanzar para los y las artistas, lo fue en su tiempo por Mozart (Elias, 1991) y lo siguió siendo para muchos.as músicos, poetas y compositores europeos.as. En el caso de Violeta se trató de un proyecto artístico que se resistió a hacer concesiones con el mercado y con las instituciones, situándose con gran coraje del lado de los oprimidos (el pueblo, el campesino, el indígena) en un ámbito en el cual aún no existían nociones como la de worldmusic -ni en las prácticas, ni en las ideas- en que se valorizan las producciones musicales alejadas del mainstream. La noción de folclor, a su vez, era menospreciada, ya que se situaba del lado del pueblo inculto o bien constituía una representación del pueblo creada por las elites (Salinas, 1991). Paradójicamente esta misma categorización rígida de géneros y estilos musicales, dejó el espacio para que artistas como Violeta lograran una conexión con la modernidad a través la cultura de aquellos.as considerados como inferiores.

10 La contribución de Paula Miranda sobre este punto es fundamental para entender la ampliamente desconocida relación que tuvo V. Parra con la cultura indígena. La labor antropológica de recopilación de los cantos mapuches que V. Para realizó en a fines de los años 1950 marcó su posterior visión de la cultura popular chilena anticipando en gran medida el paradigma intercultural actual (Miranda et al., 2017) ${ }^{4}$.

11 Del mismo modo y sin ninguna duda, V. Parra recibió y elaboró la influencia de una familia sensible a las artes, con un padre profesor de música y varios.as hermanos.as que practicaban la música, el baile y la poesía. Destacan aquí las fecundas colaboraciones artísticas con su hermano Nicanor Parra (1914-2018) poeta recientemente fallecido, quien le mostró la dirección de los antipoemas, que se ella transformó en anticueca, permitiendo hacer una innovación en que se articulaban la modernidad y la cultura popular. Esta voluntad artística de fusionar registros es analizada en profundidad por Lorena Valdebenito en su contribución a este número donde analiza dos canciones escritas por V. Parra en homenaje a dos figuras femeninas disruptivas para su época, Valentina Tereshkova, la primera mujer astronauta, y la premio nobel de literatura Gabriela Mistral. 

obra, lo cual no podemos juzgar negativamente, sino más bien comprender un camino de artista y unas formas de negociación respecto de los proyectos e ideales artísticos dominantes. Su afán por valorar el mundo campesino en oposición a la ciudad tuvo como consecuencia un paulatino alejamiento de la música comercial. El folclor apareció así a la vez como novedad y como fuente de inspiración, ofreciéndole la posibilidad de reunirse con el ámbito de su niñez, dando lugar a un camino completamente opuesto a las trayectorias artísticas convencionales de los años 1930, 1940 y 1950. calificar de primitivista (sin olvidar el problema que contiene esta designación), porque habían existido ya casos como el de Gauguin, Matisse, Derain, Picasso, Vlaminck, Henri Rousseau, Wilfredo Lam (a quien también se interrogó sobre sus raíces caribeñas) y sobre todo a partir de 1948, con el art brut de Jean Dubuffet. Sin embargo, tampoco existía un lugar importante para la música folclórica moderna que se transformó en Protest song, folk song en los años 1960 y 1970 y más tarde en world music en los años 1980. enfrentó tanto en Europa como en Chile a un campo artístico, en el sentido de Pierre Bourdieu, donde tuvo que inventar su propio lugar (Dillon, 2017 y 2009). Y esto que es para Bourdieu la creación extrema, representa también la estrategia más difícil para los.as artistas, porque tiene que producirse una revolución simbólica. Ingresar y hacerse lugar nuevo en el conjunto artístico, requería de un gran coraje y de una perseverancia fuera de lo normal, era y es menos dificultoso para el artista, ocupar un género, un sitio, una estética que existe en la tradición artística ${ }^{5}$. V Parra seguramente era a la vez consiente de esta dificultad y inconsciente del todo lo que esto podía tener como consecuencia.

en su contribución Patricia Vilches analiza las "Décimas" -la obra poética central en la obra de V. Parra- mostrando el lugar que ocupan en ella la innovación, tradición, la nación y el género. De manera complementaria, la contribución de Eleni Stagkouraki a este número explora la forma en qué V. Parra a través de su pesia y música se rebeló contra el ostracismo y subalternización resultante de su condición de mujer rural y por ende "dominada".

16 El paso de Violeta por Europa ha sido objeto de múltiples mediaciones y representaciones las que cobran gran importancia para los procesos de reconocimiento y consagración de su obra en Chile y que a la vez participan de un proceso más amplio sobre la construcción del artista latinoamericano por la mirada europea. La recepción de su obra en el contexto europeo por parte de la crítica y de las instituciones culturales de la época, la exposición de su obra plástica en París en 1964, contribuye a una forma de reconocimiento tanto en Europa como en Chile.

17 La contribución de Daniela Fugellie en este número sobre la famosa exposición realizada en el Museo de Artes Decorativas del Palacio del Louvre en 1964 nos permite esclarecer este episodio central en la vida de V. Parra. La autora sostiene que dicha exposición responde ante todo a una estrategia de la artista de búsqueda de reconocimiento en su país natal a partir de la movilización del capital simbólico que representa el Museo del Louvre en la elite chilena tan dominada en su época por una visión eurocentrista de la cultura. Y ello paradójicamente con el objetivo de introducir elementos de la cultura 
popular local en la idiosincrasia chilena, en otras palabras, de "descolonizar" la cultura nacional chilena. Se trató de alguna manera de utilizar el eurocentrismo contra sí mismo.

Este estudio se complementa con la contribución de Isabel Plante donde se analizan las características estilísticas, temas y motivos de las arpilleras y pinturas. La autora nos muestra como la artista conectó lo vernáculo y lo internacional, lo popular y lo moderno a partir del estudio de las influecias y circulación de la obra visual de V. Parra que fue expuesta en París. De esta manera, este número especial pretende esclarecer uno de los momentos clave de la trayectora de V. Parra que pese a ser ampliamente conocido ha sido sujeto de innumerables mitos y conjeturas.

En efecto, la recepción de Violeta en Europa puede ser analizada a partir de una cierta idea de exotización de los artistas latinoamericanos en Europa promovida a partir de los movimientos que atravesaron el siglo XX en dirección del indigenismo y de lo espontáneo. Asimismo, nos interesaremos por la propia construcción de una carrera de artista en ese contexto y por las estrategias y recursos movilizados para existir como artista latinoamericana en el medio europeo, y en su regreso a Chile. En este sentido, la contribución de Stefano Gavagnin sobre la recepción de la obra de V. Parra en Italia nos permite entender cómo la circulación de su obra no puede ser disociada de la resignificación de la dimensión política de su figura tras el golpe de estado militar de 1973.

20 Probablemente no exista aún una codificación social clara para dar cuenta del papel artístico y profesional que asumió Violeta Parra. Ganadora de premios folclóricos, cantante de velorios, animadora de programas de radio, empresaria cultural, artista plástica, sujeta de documentales internacionales, profesora de folclor en la Universidad de Concepción e investigadora autodidacta. La inestabilidad formó parte de su herencia artística e institucional a partir de la cual tiene que inventar cada día su profesión y buscar un reconocimiento público e institucional fuera de los circuitos predeterminados. En su vida puede reconocerse una forma de nomadismo social, en que abunda el rechazo y la incomprensión, no siendo fácilmente contratada por sellos discográficos ni programada por salas de espectáculo, ante lo cual se ve obligada a renovar, improvisar permanentemente, trasladarse, viajar, autoproducir giras, festivales, concursos y conciertos donde prima la irregularidad y la variedad de situaciones.

\section{Proceso de interpretación}

21 Esas dificultades, bien conocidas desde la invención de la vida de artista en el siglo XIX en Francia, han sido descritas por Pierre Bourdieu $(1975 ; 1992)$. V. Parra hizo una trayectoria impregnada de las contradicciones propias de este contexto externo que se reflejaron de manera interna en sus elecciones de vida (como sus viajes a Europa, una vida amorosa rica por su época, una variedad de prácticas artísticas) y sus elecciones artísticas. Son de cierta forma "los chubascos" de los cuales habla en Gracias a la vida (1966). Podemos intentar exponer algunas de las contradicciones internas que corresponden también al proceso de interpretación de su persona como artista: por ejemplo, contradicciones entre una figura percibida como autodidacta, lo dice ella también, y muy educada a la vez por su familia, su ámbito campesino y sus estudios en Santiago. V. Parra puede decir a veces que nunca fue a la escuela, que a penas sabe escribir. Esta imagen de poetisa ingenua se opone a la de investigadora capaz de elaborar análisis antropológicos del todo complejos, más en los 1950. Podemos hablar entonces de diversas formas de escenificar una 
identidad de artista que sabe adaptarse a distintos contextos con gran plasticidad, recurriendo a la imagen de una artista espontánea, autodidacta, casi campesina "primitiva", lo que se exacerba durante su estadía en Europa, como puede percibirse en las entrevistas que dio para la televisión suiza.

Aceptar estas formas de auto-representación como la verdad última de la artista sería como decir que los músicos de jazz del movimiento Bebop de los años 1950 eran primitivos. Por cierto, ella no hizo estudios de conservatorio, pero la tradición directa le fue enseñada, de la misma manera que se transmite el flamenco en España en familias gitanas o en las danzas y músicas tradicionales africanas de Brasil (Bastide, 1960); es decir que la tradición oral no tiene nada de inculta y menos de autodidacta ya que se realiza a través de complejos a procesos de inmersión cultural.

Este conjunto de contradicciones a la vez internas y externas nos permiten afirmar que la vida de todo.a artista está permanentemente sometida a fuerzas sociales en un juego de exclusión/ignorancia. Al mismo tiempo los.as artistas se confrontan a la necesidad de sobrevivir y a la vez lograr ser estimados, valorados y reconocidos por los mundos del arte sean estos institucionales o a contra-corriente de los circuitos oficiales. En el caso de Violeta sin duda sus profundas convicciones y su compromiso a la vez cultural, social y político la motivaron a recopilar, grabar y cantar los repertorios del pueblo en una época en que estas no gozaban de una valoración importante. Más tarde la adaptación y transformación de las músicas folclóricas las hizo audibles por un público masivo permitiéndoles ingresar a mercados que valoraron cada vez más la diversidad y la alteridad. Su partida se produjo antes de que este movimiento de reconocimiento del folclor se hiciera visible como forma de una cultura global. Así ejemplos como el blues del sur de Estados Unidos, muestran cómo la migración de géneros y sonoridades fueron trazando una particular geofrafía de la música pasando por Inglaterra en el rock-pop de los Beatles y de los Rolling Stones, en los años 1950-1970. Así se estableció un complejo entramado entre cultura popular y culturas juveniles a partir de tránsitos entre cultura afro- estadounidense y cultura blanca-estadounidense donde como ha pasado con otros géneros el paso por Europa contribuyó ampliamente a su difusión masiva y a su reconocimiento. V. Parra no alcanzó a ver este proceso que también siguió su música.

Las entrevistas a la prensa de V. Parra nos hacen ver una trayectoria que nunca fue rectilínea, sino que en extremo sinuosa, llevándola a tomar varios papeles en una profesión que inventaba su propio recorrido. En la primera entrevista conocida -que se puede leer en el libro de Marisol García (2016)- de 1954, aparece Violeta con 37 años, se presenta como una especialista, antropóloga del folclor chileno, contextualiza las músicas, busca la reconstitución de un patrimonio y también compone a la manera del folclor chileno (70 composiciones originales en esta época, ya un número importante): esta ya la contradicción entre un papel de recopiladora y de artista libre, que compone en genero folclórico, es decir que perpetua de modo contemporáneo el folclor chileno. Cierto con letras más actuales y autobiográficas, pero con una forma colectiva, con lo que ella llama "el genio del pueblo". Es decir, no totalmente con el genio del artista. Dos modelos de creación se enfrenten desde el principio de su trayectoria.

Bourdieu (2014, pp. 85-88) sostiene que toda producción artística es mitad consiente y mitad inconsciente, una afirmación que podemos constatar analizando la trayectoria de Violeta Parra. Si consideramos que los y las artistas desarrollan su trabajo en un ámbito cultural que podemos llamar con Bourdieu el campo artístico, sabremos que éstos buscan posicionarse en un lugar por negociar su lugar, en contra o en continuación con una 
tradición y en contra o en colaboración con la creación contemporánea. En ese tránsito se van estableciendo alianzas como con otros músicos, investigadores.as y artistas como fueron Margot Loyola, Víctor Jara o el artista visual Julio Escámez, instituciones como la Universidad de Concepción, el sello discográfico RCA Víctor. Asimismo, se instauran confrontaciones que en el proyecto cultural y político de Violeta vienen a afirmarse la defensa de la música chilena y de la cultura popular en oposición a las músicas foráneas y comerciales donde destacan figuras como Paul Anka. Se trata de una directiva en el sentido de Baxandall (1989) en que el artista negocia continuamente con su propia cultura. En Violeta las producciones artísticas del mundo popular, rural indígena y pobre devienen a la vez su meta y su principal recurso artístico.

Como hemos visto en Violeta la posición anti-artística reviste una serie de ambivalencias. En ciertos espacios parece predominar su actividad como recopiladora y antropóloga autodidacta cuyo objetivo es salvaguardar un conjunto de saberes musicales, sonoros y poéticos como un patrimonio del bajo pueblo que no ha sido reconocido. Esta actitud nos recuerda la posición del artista investigador, de un escritor como Zola en la Francia en el siglo XIX o Annie Ernaux, escritora francesa contemporánea quien dice que no se reconoce como una autora de literatura al tiempo en que publica una prestigiosa editorial como Gallimard. La posición particular del artista puede ubicarse a contracorriente de su propia definición como tal, privilegiando otras etiquetas como la de científico, investigador, hombre o mujer del pueblo o en palabras de la propia Violeta "uno más". Estos tránsitos resultan apasionantes si consideramos que se trata de tensiones de identidad que van en contra la ideología del artista creador como totalidad y permanencia. Sin embargo se trata de una afirmación de aquello que hemos reconocido más arriba como el régimen de singularidad relacionado con la figura del artista romántico y maldito que por decisión propia o del sistema del arte queda fuera del juego artístico oficial.

Nos queda entonces la pregunta por el sentido de la práctica artística que producen los actores de los mundos del arte: los críticos, las instituciones del arte, el público, los periodistas, los políticos y los propios.as artistas. Como hemos visto en el caso de Violeta estas tensiones y luchas del campo artístico no se dan únicamente entre productores culturales y comentadores.as, sino que también interpelan a la propia artista sobre el sentido de su obra y de su proyecto artístico y político, a la manera planteada por Brecht acerca de quién sirve el arte.

Y es que la opción por convertirse en artista y renunciar al papel romántico o consensual se convierte en el caso de Violeta en una toma de posición política de rechazo del individualismo artístico en favor de lo colectivo. Las entrevistas de Violeta presentadas en el trabajo de recopilación esencial de Marisol García (2016), permiten seguir el curso discursivo de su trayectoria, permitiendo dilucidar cómo la cantautora explico y dio sentido a su práctica.

\section{Vaivenes simbólicos entre la periferia y la capital}

Si nos detenemos en los recorridos geográficos de Violeta constatamos que su migración a Santiago desde su región natal tuvo por objetivo perfeccionar su aprendizaje del género musical español. Según narra en una de sus entrevistas de 1954, había sido galardonada con un premio al "folclor español" en 1944. La posibilidad de intentar consolidarse en ese género -en esa época valorado- le habría procurado tal vez un camino más exitoso y 
seguro que la aventura que se decidió a emprender más tarde. La posibilidad de dedicarse a la música popular chilena desde su niñez era difícil de visualizar desde un principio sentido ya que se trataba de un rol artístico que no existía aquella época y donde ella y Margot Loyola fueron precursoras. El oficio de cantoras populares y payadores (poetas, improvisadores y músicos de tradición oral) se desplegaba en fiestas populares, religiosas y cotidianas y no se relacionaban con la idea moderna del arte. La influencia de su familia, de su hermano Nicanor y de las nuevas influencias que fue encontrando en los circuitos artísticos y políticos que frecuentaba la llevaron poco a poco a tomar conciencia de la riqueza del arte popular en una época en que el concepto empezaba apenas a plantearse a través de intelectuales, artistas y militantes, donde resalta la figura señera de Tomás Lago. En torno a los 1950-1953, Violeta comienza a investigar un universo cultural que conocía desde pequeña, pero esta vez como antropóloga autodidacta, en el modelo de investigadoras/artistas de Margot Loyola.

El imaginario y los mapas cognitivos de Violeta nos permite intentar comprender su actitud artística y su relación compleja con el arte en su definición más romántica y burguesa (como originalidad, individualismo y talento único). Podemos hacer un listado de estas clasificaciones siguiendo cómo V. Parra califica al arte comercial y el arte popular a través de las entrevistas dadas a las radios, los periódicos y la televisión. En estos espacios se refiere al folclor falso y comercial y canciones en tal registro lexical, con tonos menores, sobre la ciudad, lo urbano, música romanticona, de letras horrendas, rebuscadas, de "flor azul", propias de plaza de armas, un folclor mezclado e impuro, con estilización, disfraz musical, con gorgoreos en la interpretación cantada y con sonrisas postizas. En oposición se propone defender lo que ella llama "nuestro autentico folclor" caracterizado por tonos mayores, del campo, del campesino, de la costumbre, de temas infinitos con alegría y tristeza, con voz sufrida, con legitimidad, con autenticidad, de folclor chileno, de tradición transmitida de boca en boca, de lo antiguo, transmitido por cada generación, de lo nacional, del alma del pueblo, del alma de la cantante, del folclor puro, de música que cura los problemas, de aspiraciones y deseos del pueblo, de lo indígena, de "una alma tan antigua", en definitiva de lo popular de alta calidad.

Conclusión

Si tomamos el modelo Gisele Sapiro (2002), podemos concluir que V. Parra desarrolló una actividad al principio entre ciencia y arte a la manera de un Zola (Charles 2002), dictando cursos de folclor en la Universidad de Concepción y al mismo tiempo situándose como una cantautora (antes de que la noción misma comenzara a existir). En cuanto a su actividad musical podemos dar cuenta de un prematuro interés por el folclor que más tarde se "primitiviza" en el espejo europeo adaptándose y negociando con una cierta expectativa de exotización que rehúye y reinventa. Termina por fin en una tentativa de sedentarización de su actividad en el centro cultural en La Reina, en donde se propone consolidar su ambicioso proyecto de Universidad del folclor a partir de la recreación de un modo de vida comunitario donde convergieran la ruralidad, el arte y el mundo popular.

En el campo de su arte en los años 1930, el folclor como producción asociada al mundo campesino e indígena, no goza de un reconocimiento importante. En este género los premios y festivales son muy especializados; el proyecto de V. Parra busca dar otro sitio al folclor chileno, y hoy podemos decir que logró este objetivo, consiguiendo una mayor valorización de este arte del bajo pueblo tanto de parte de los críticos y estudiosos como para una nueva generación de músicos. 
En su trayectoria hay una multiactividad según su manera de devenir artista y de las distintas épocas de su vida personal y artística. Oscilando entre distintos oficios y roles: de recopiladora-antropóloga a autora de canciones, de profesora de folclor, a cantante de radio, de conciertos, en restaurantes, en salas, en teatros, a artista que hace giras internacionales, artista plástica casi de arte bruto o outsider lidiando en permanencia con la precariedad de la vida de artista. Violeta intenta finalmente devenir artista-gestora de una empresa cultural y social a partir de otro modelo al propuesto por el mercado cultural y la industria del entretenimiento.

Con su centro cultural se termina su trayectoria, probablemente el reconocimiento estatal le hubiese dado el soporte para la permanencia del centro de La Reina, logrando sustentar su compromiso social, político y artístico. Su suicidio pudo deberse en parte, a la desesperanza y desazón provocadas por la dificultad de consolidar tal proyecto. Tampoco se trató de un modelo cultural que tuviera éxito más tarde en Chile, mucho menos con el golpe de estado que acechó al país donde se impusieron los valores del mercado, la competencia y el individuo, claramente en oposición a aquellos de la comunidad, la igualdad y la justicia que representaban a Violeta. ¿Podríamos decir hoy que Violeta encarnó en su trayectoria el papel de artista comprometida? Es sabida su cercanía con el ideario del Partido Comunista y en ella puede reconocerse una clara identificación con las clases trabajadoras. En sus canciones y entrevistas defiende sin concesiones las ideas de justicia, del pueblo, de los pobres contra el privilegio de unos pocos, (los políticos, "los presidentes”, “abigorrádicos en los sillónicos”). Violeta declara su clara sensibilidad del lado de los oprimidos, defiende el valor del colectivo, de las luchas contra la injusticia y del genio del pueblo.

Su obra plástica es presentada por ella y sus críticos como practicas improvisadas, instintivas, que "salen así": una autodefinición de autodidacta que debe ser también objetivada a fin de lograr un análisis más profundo de los alcances de su obra y trayectoria. Aprendió música y en términos de su arte visual podemos ver que el bordado y las arpilleras son técnicas encajadas en el género femenino. Sus últimas producciones plásticas nos demuestran que, al final de su vida, con su tristeza personal en lo íntimo, logró conciliar dos papeles artísticos contradictorios muy pocas veces mezclados en la trayectoria de un artista. Balzac era un empresario de la literatura, Zola un científico escritor investigador (pero que termino en tono profético como indica Christophe Charles (2002), V. Parra termina igualmente algunos rasgos típicos de la artista romántica, con la espontaneidad, la pasión, el tópico también de la incomprensión, donde el papel artístico y social es también la tragedia, relacionado también la búsqueda de la autonomía: pero en este caso en oposición a la idea de un arte por el arte.

7 Sabiendo con Norbert Elias (1991) que el habitus social no tiene ninguna contradicción en elegir al individuo artista como configuración autorizada por la sociedad de una persona a parte y diferente, ella desarrollo en Chile el papel innovador, a la vez del artista en ruptura, moderno, y comprometido, es decir que Violeta dio la espalda al reconocimiento de la sociedad burguesa e institucional chilena. Como en el caso de Mozart, descrito por el propio Elias, V. Parra no encajó una estabilidad social en la sociedad de su tiempo, no quería cantar para entretener sino para esclarecer las conciencias, no quería seducir sino denunciar la injusticia, no quería parecer culta, sino espontánea.

El propósito fue entonces el de articular el oficio de artista de manera romántica y libre con el compromiso de hacer un arte por la defensa del pueblo. Para ello la carpa de La Reina representó una empresa cultural que era más bien una utopía colectiva de 
convivencia, una utopía de sociedad centrada en el compartir y en la puesta en valor de lo artístico folclórico accesible a todos y todas. Esta utopía de comunidad, de fusión con el pueblo, se confrontó como lo dice ella misma al equilibrio económico. La contradicción se dio entre el sueño de un pueblo unido y la necesidad de convocar a un público que permitiese sustentar esta empresa cultural colectiva. En las últimas entrevistas se aborda claramente esta tensión.

Al fin y al cabo, las contradicciones del inicio vuelven a hacerse presentes al final: las tensiones entre el deseo de ser artista individual o el de ser una mujer del pueblo como parte de un colectivo utópico. El modelo del artista al servicio del pueblo es más bien un modelo socialista. Históricamente el estatuto de artista libre se creó con la colusión y la ayuda de las elites aristocráticas y económicas (familias nobles, papas, príncipes, notables, burgueses, banqueros). Se trató de un papel individual basado en el invento del talento o del genio como manera de negociar su libertad. La economía de mercado hace que el público, del cual habla V. Parra, es el maestro de la carrera de un artista, después de los premios y del reconocimiento entre artistas o de parte de los especialistas. Violeta al final buscó dirigirse al público joven para su centro cultural como foco de su anhelo de transmisión de la cultura popular a las nuevas generaciones.

Desgraciadamente su partida se produjo antes de los movimientos juveniles y estudiantiles del 1968 en los cuales seguramente, hubiera tenido un papel, pensamos, importante. No en vano su hijo Ángel compuso una de las canciones más emblemáticas del período titulada "Qué vivan los estudiantes". La Reforma estudiantil chilena iniciada 1967, así como mayo del 68 francés fueron tentativas de utopía que pusieron en escena otro modelo de sociedad representado por una música pensada más para congregar que para separar las clases sociales. Las canciones de Violeta Parra fueron cantadas entonces y más tarde como resistencia a la dictadura y aún en estos tiempos, con gran reconocimiento y éxito. Desde Chile pudimos atestiguar la enorme presencia de su figura en el mayo feminista de 2018 en que muchas colectivas llevaron su nombre y entonaron sus canciones de amor y de justicia como canto de esperanza por una sociedad mejor.

\section{BIBLIOGRAFÍA}

BASTIDE, R. (1960), Les religions africaines au Brésil, PUF, París.

BAXANDALL, M. (1989), Modelos de intención. Sobre la explicación histórica de los cuadros, Herman Blume, Madrid.

BOURDIEU P. (1975), “L'invention de la vie d'artiste”, in Actes de la recherche en sciences sociales, $n^{\circ} 1$, París.

BOURDIEU, P. (1992), Les règles de l'art, Seuil, París.

BOURDIEU, P. (2014), Manet. Une révolution symbolique, Seuil, París. 
CHARLES C. (2002), “De la science à la prophétie : situation de Zolà”, in PINTO, E., Penser l'art et la culture avec les sciences sociales. En l'honneur de Pierre Bourdieu, Éditions de la Sorbonne, París.

CONSEJO NACIONAL DE LA CULTURA Y LAS ARTES DE CHILE (CNCA) (2017), Violeta Parra, después de vivir un siglo, CNCA, Santiago.

DILLON, L. (2017), Violeta Parra. Life and Work, Tamesis, Suffolk.

DILLON, L., "Defiant Art: The Feminist Dialectic in Violeta Parra's Arpilleras", en TAYLOR, C. (2009), Identity, Nation, Discourse: Latin American Women Writers and Artists, ed. Claire Taylor, Cambridge Scholars, Newcastle, pp. 53-66.

ELIAS, N. (1991), Mozart. Sociologie d'un génie, Seuil, París.

FUNDACIÓN VIOLETA PARRA (ed.) (2007), Violeta Parra. Obra visual, Ocho libros, Santiago.

GARCÍA, M. (2016), Violeta Parra en sus palabras. Entrevistas (1954-1967), Editorial Catalonia, Santiago.

HEINICH, N. (2005), L'élite artiste. Excellence et singularité en régime démocratique, Gallimard, París.

HERRERO, V. A. (2017), Después de vivir un siglo. Una biografía de Violeta Parra. Penguin Random House, Santiago.

MIRANDA, P., LONCON, E., RAMAY, A. (2017). Violeta Parra en el Wallmapu. Su encuentro con el canto mapuche, Pehuén, Santiago.

MUSEO VIOLETA PARRA (ed) (2015), Catálogo Exposición Permanente. Violeta, humana y divina, Santiago, http://museovioletaparra.cl//wp-content/uploads/2015/10/

MVP_Catalogo_Revisado.pdf

OVIEDO, C. (1990), Mentira todo lo cierto: trás la huella de Violeta Parra, Editorial Universitaria, Santiago.

PAULME D. (1991), « Le primitivisme dans l'art », en BONTE P., IZARD M., Dictionnaire de l'ethnologie et de l'anthropologie, Presses Universitaires de France, Paris, pp. 601-602.

SALINAS, M. (1991), Canto a lo divino y religión del oprimido en Chile, Rehue, Santiago.

SAPRIO, G. (2002), "De l'écrivain d'Etat à l'intellectuel”, in PINTO, E., Penser l'art et la culture avec les sciences sociales. En l'honneur de Pierre Bourdieu, Éditions de la Sorbonne, París.

\section{NOTAS}

1. Cabe destacar igualmente el número especial en el libro colectivo editado por el CNCA en 2017, en el que se exploran con un objetivo divulgativo diferentes aspectos habitualmente olvidados de su obra y su figura de la mano de autores como Gastón Soublette, Bernardo Subercasaux, Maximiliano Salinas y Sonia Montecino entre otros. El presente número incluye una reseña de esta obra (CNCA, 2017).

2. En 1968, la Vicerrectoría de Comunicaciones y Extensión de la Universidad Católica de Chile organizó en su Casa Central una exposición dedicada a Violeta Parra y una mesa redonda moderada por Enrique Bello. Esta mesa dio origen a una publicación en diciembre de 1968 en la Revista de Educación y, en febrero de 1971, por El Musiquero, en el cuarto aniversario de su muerte. Participaron, entre otros, José María Arguedas, Margot Loyola, Teresa Vicuña, José Ricardo Morales y José María Palacios. 
3. Ver Denise Paulme, «Le primitivisme dans l'art », en Bonte Pierre, Izard Michel, Dictionnaire de l'ethnologie et de l'anthropologie, p. 601-602 (PUF, 1991).

4. El presente número incluye una reseña de esta obra.

5. Como lo dice Bourdieu (2014, p. 87): "Según el ámbito, las personas van a tener un espacio de posibles más o menos amplios, más o menos cuantificados.".

\section{RESÚMENES}

Violeta Parra est aujourd'hui l'une des artistes chiliennes les plus internationalement reconnues. Néanmoins, l'étendue de son travail a été à peine analysée et reconnue par la culture dominante, tant dans les milieux artistiques qu'académiques. Nous proposons une série d'hypothèses, formulées à partir de la sociologie de l'art et de la culture, pour expliquer ce fait, cherchant à rendre compte de la singularité d'une trajectoire à la fois artistique et sociale. Sa situation de paysanne et la faible institutionnalisation du champ artistique chilien de son époque ont amené V. Parra à se lancer dans une carrière d'artiste où des éléments disparates, de différentes géographies et époques, ont été fusionnés dans le cadre d'un objectif mondial d'émancipation et d'autodétermination de la culture chilienne. Sur la base de ces hypothèses, nous présentons et discutons les textes qui composent ce numéro spécial.

Violeta Parra representa hoy en día una de las artistas chilenas más reconocidas internacionalmente, sin embargo el alcance de su obra ha sido escasamente analizado y reconocido por la cultura dominante tanto en los circuitos artísticos como académicos. Planteamos una serie de hipótesis, formuladas desde la sociología del arte y de la cultura, para explicar este hecho, buscando dar cuenta de la singularidad de una trayectoria a la vez artística y social. Su condición de mujer campesina y la débil institucionalización del campo artístico chileno de su época condujeron a V. Parra a emprender una carrera de artista donde se fusionaron elementos dispares provenientes de diferentes geografías y épocas en el marco de un objetivo global de emancipación y autodeterminación de la cultura chilena. A partir de estas hipótesis presentamos y hacemos dialogar entre sí los textos que componen este número especial

Violeta Parra represents today one of the most internationally recognized Chilean artists, however the scope of her work has been scarcely analyzed and recognized by the dominant culture in both artistic and academic circles. We propose a series of hypotheses, formulated from the sociology of art and culture, to explain this fact, seeking to account for the uniqueness of a trajectory that is both artistic and social. Her condition as a peasant woman and the weak institutionalization of the Chilean artistic field of her time led V. Parra to embark on an artist career where disparate elements from different geographies and epochs merged within the framework of a global goal of emancipation and self-determination. the Chilean culture. Based on these hypotheses, we present and discuss the texts that make up this special issue. 


\section{ÍNDICE}

Keywords: Artist carrier, Chile, folklore, sociology of culture, Violeta Parra, artistic trajectory.

Palabras claves: Chile, folclore, sociología de la cultura, trayectoria de artista, Violeta Parra, trayectoria artística

Mots-clés: Carrière de l'artiste, Chili, folklore, sociologie de la culture, Violeta Parra, trajectoire artistique.

\section{AUTORES}

\section{MARISOL FACUSE}

Doctora en Sociología del arte y la cultura y Master II en Sociología del arte y el imaginario (Universidad de Grenoble), Magíster en Filosofía y Socióloga (Universidad de Concepción). Profesora asociada del Departamento de Sociología de la Facultad de Ciencias Sociales de la Universidad de Chile y coordinadora del Núcleo de Sociología del Arte y de las prácticas culturales. Ha coordinado el Grupo de Trabajo de Sociología del arte y la cultura de la Asociación Latinoamericana de Sociología (ALAS) y de Sociología del arte del Congreso chileno de Sociología y pertenece al Comité organizador del RC de Sociología del arte en la Asociación Internacional de Sociología (ISA). Sus principales investigaciones se relacionan con arte y política, culturas populares, músicas inmigrantes y mestizajes culturales.

Universidad de Chile

\section{ERIC VILLAGORDO}

Maître de conférences en pratiques plastiques contemporaines, Sociologue de l'art, Université Paul-Valéry Montpellier 3, Membre du laboratoire RIRRA21, Docteur en Arts et sciences de l'art (Paris I, Panthéon-Sorbonne), Maîtrise en Sociologie (Université Victor Segalen, Bordeaux), agrégation d'arts plastiques. Ses trois axes de recherche sont les processus de création artistique aujourd'hui dans le domaine des arts visuels (trajectoire et vie des artistes), l'éducation à l'art et à la culture (notamment par l'enquête culturelle, en collaboration avec l'UQAR au Québec et la faculté d'Éducation de l'université de Montpellier), les rapports entre la bande dessinée et la société (politique, récits nationaux, représentation de la société, processus mémoriel, dystopies). Université Paul Valéry Montpellier III

\section{JUAN ENRIQUE SERRANO MORENO}

Doctor en Ciencia Política y Licenciado en Derecho y en Ciencia Política por la Universidad Paris I Panthéon-Sorbonne, ha impartido docencia en universidades de Chile, España y Francia y ha desarrollado investigaciones sobre políticas de memoria, movimientos sociales, derecho administrativo y política criminal. En paralelo, ha ejercido como abogado y analista de políticas públicas. Actualmente desarrolla una investigación sobre la integración de Hong Kong en la República Popular de China. Facultad de derecho, Universidad Autónoma de Chile 